\title{
Investigation of Factors Affecting the Efficiency of Carbon Dioxide Removal in a Single Perforated Sieve Tray Column
}

Sarmad foad jaber, Yuosif M. Abdul wahab and Sami M. Zboon

Chemical Engineering Department/ College of engineering/Baghdad University

\section{Abstract}

An experimental work was carried out for the recovery of carbon dioxide in monoethanolamine solution (MEA) using pilot plant of perforated sieve tray column. The effect of MEA concentration, carbon dioxide ratio in the gas phase, liquid flow rate, gas flow rate and $\mathrm{CO}_{2}$ loading in the absorption solution was investigated. The results show that the efficiency of recovery increased by increasing the concentration of MEA and better removal efficiency can be achieved by increasing the liquid flow rate and the contact time between $\mathrm{CO}_{2}$ and the absorbent and that can be happened by decreasing the air flow rate.
Key words: sieve tray, monoethanolamine, absorption, carbon dioxide

\section{Introduction}

The major $\mathrm{CO}_{2}$ sources are industrial byproducts which include natural gas sweetening, synthesis gas production and flue gases which include fossil fuelfired power plants, industrial furnaces, cement plants, engine exhausts and lime kiln exhausts. [1]

Monoethanolamine (MEA) has a long history of commercial $\mathrm{CO}_{2}$ recovery with various feeds including flue gases. Uninhibited MEA is generally limited by corrosion problems to about 15 20 wt $\%$ MEA. Furthermore, 
many applications rely on the presence of hydrogen sulfide in the feed to provide a passivating layer of iron sulfide to reduce carbonic acid corrosion. This protection is absent in flue gas systems where $\mathrm{H}_{2} \mathrm{~S}$ is not present. [2]

Recently 30 wt \% MEA concentration levels were made feasible by the addition of corrosion inhibitors. Jou et al (1995) obtained solubility data of $\mathrm{CO}_{2}$ in $30 \mathrm{wt} \%$ MEA. Also, studies by Austgen (1989) corroborated well with the VLE data presented by Jou et al. In addition operating data for large MEA plants are reported in Kohl (1997). [2]

Aboudheir (1998) investigate the factors affecting the often requires treating in order to achieve a $\mathrm{CO}_{2}$ cleanup target of less than $1 \%$ by volume. [5]

Sarmad (2009) find that to improve high absorption rate from gas phase to a liquid absorbent using perforated sieve absorption of $\mathrm{CO}_{2}$ using pilot packed bed column with MEA solution and the results show that in general the absorption rate increases as the liquid flow rate increase and that was for all kind of packing materials.[3]

Fadil (2008) shows that not only the operation condition of the absorption process of $\mathrm{CO}_{2}$ may affect the rate of recovery of the gas but even the additive materials such as surfactant (dodecyl benzene sulfuric acid sodium (DBS)) can reduces the rate of absorption of the gas.[4]

The removal of carbon dioxide from raw natural gas is an essential step for meeting cleanup targets. The majority of raw gases contains a significant amount of $\mathrm{CO}_{2}$ and tray column it's important to reduce the flow rate of the gas mixture as possible with the operating condition of the column in order to increase the contact time between the 
absorbed gas and the absorbent liquid. [6]

Many studies takes place to investigate the efficiency and operating condition of the perforated sieve tray column for absorption process, the newest one that carried out by Hemiri (2009) study the efficiency of perforated sieve tray column for absorption process using the technique of artificial neural network. [7]

The aim of this study was to investigate the capture efficiency of MEA to $\mathrm{CO}_{2}$ in a perforated sieve tray column. A pilot scale plant was used in this study in the hope that its applicability extends to industrial scale solution systems for removing $\mathrm{CO}_{2}$ where most of available previous studies were carried out using packed bed column.

\section{Experimental work}

The absorption of carbon dioxide takes place in a pilot plant of perforated sieve tray column that shown in figure 1.

The absorption process was conducted in a counter current mode. At steady state operation for each run the liquid with known concentration of absorbent (MEA) pass through a calibrated rotameter to control the amount of liquid flow rate that inter the absorption column from the top end of the column according to the operating condition of the run to come in to contact counter currently with the mixture of known ratio of $\mathrm{CO}_{2}$ and air which is mixed together before enter in to inside from the bottom of the column. The outlet liquid composition was analyzed for its $\mathrm{CO}_{2}$ loading to understand the efficiency of the process. 


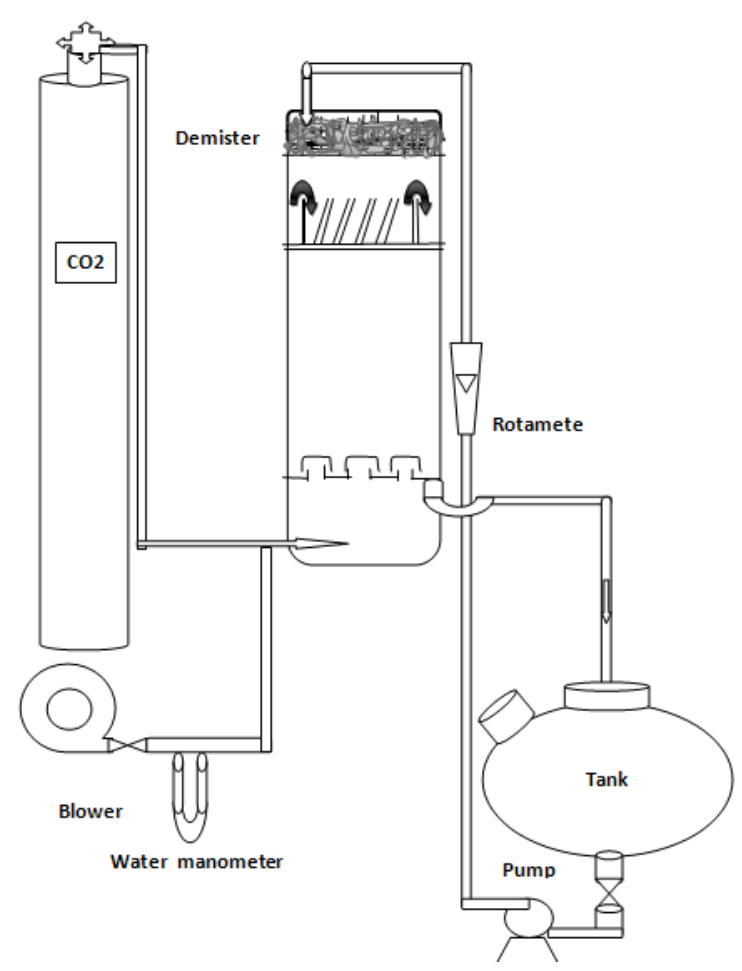

Figure (1) Schematic flow diagram of the absorption unit

\section{$\underline{\text { Result and Discussion }}$}

Figure 2 shows that by increasing the MEA concentration, the removal efficiency will increase but that effect is not as great as might be expected. It's clear from the results that increase MEA concentration from $18 \mathrm{wt} \%$ to 30 wt\% the $\mathrm{CO}_{2}$ increase the removal efficiency from $62 \%$ to $69 \%$ with only $7 \%$ increasing achieved, also the increase of MEA concentration from 30wt $\%$ to $55 \mathrm{wt} \%$ will increase the removal efficiency from $69 \%$ to $70 \%$. that happened because of the acid-gas vapor pressure is higher over more concentrated solutions at equivalent acid gas/amine mole ratio and also when the same quantity of $\mathrm{CO}_{2}$ is absorbed in a smaller volume of solution the heat of reaction results case a greater increase in temperature and that will increase the $\mathrm{CO}_{2}$ vapor pressure in the solution. [8] 


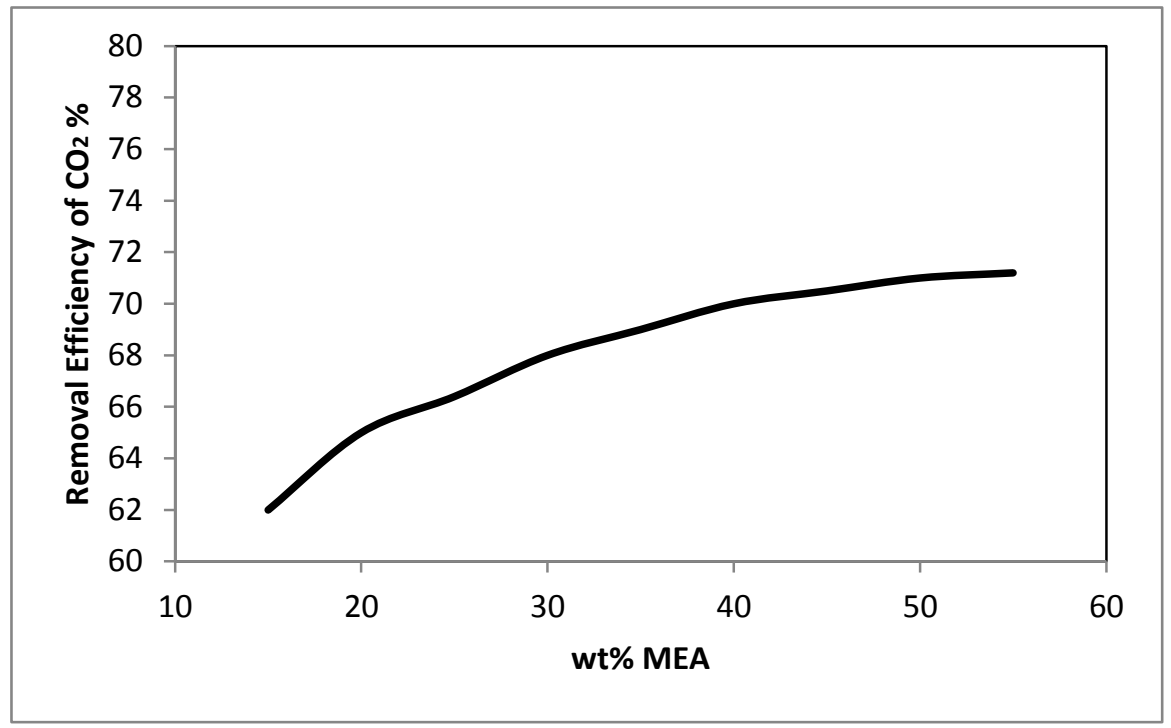

Figure (2) the effect of MEA concentration on the efficiency of $\mathrm{CO}_{2}$ removal

Figure 3 show that when the liquid flow rate increased the absorption rate (Removal efficiency) will increase because of the higher liquid mass transfer coefficient and quantity of free mono ethanol amine (the absorbent). [3]

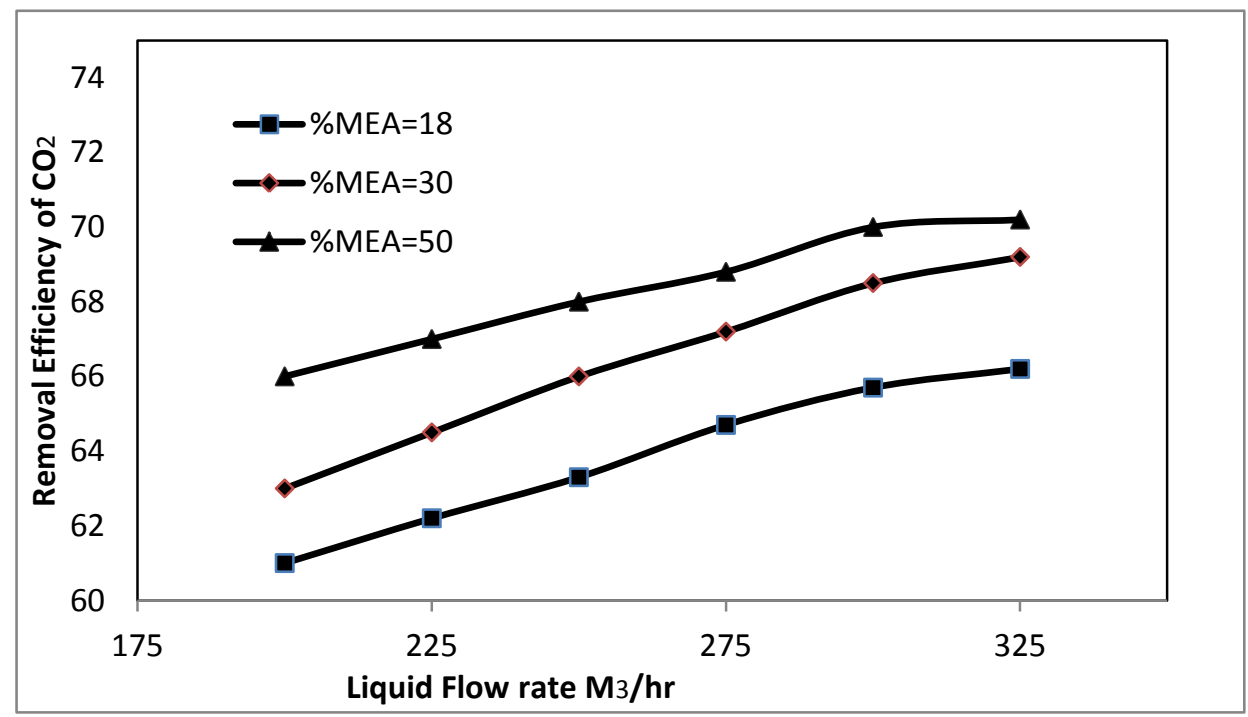

Figure (3) the effect of liquid flow rate on the removal efficiency for $\mathrm{CO}_{2}$ at different MEA concentration 
Figure 4 shows that the reduction of air flow rate will increase the absorption rate by increasing both of the amount of $\mathrm{CO}_{2}$ to air in the gas phase and the contact time between the gas being absorbed and the absorbents liquid.

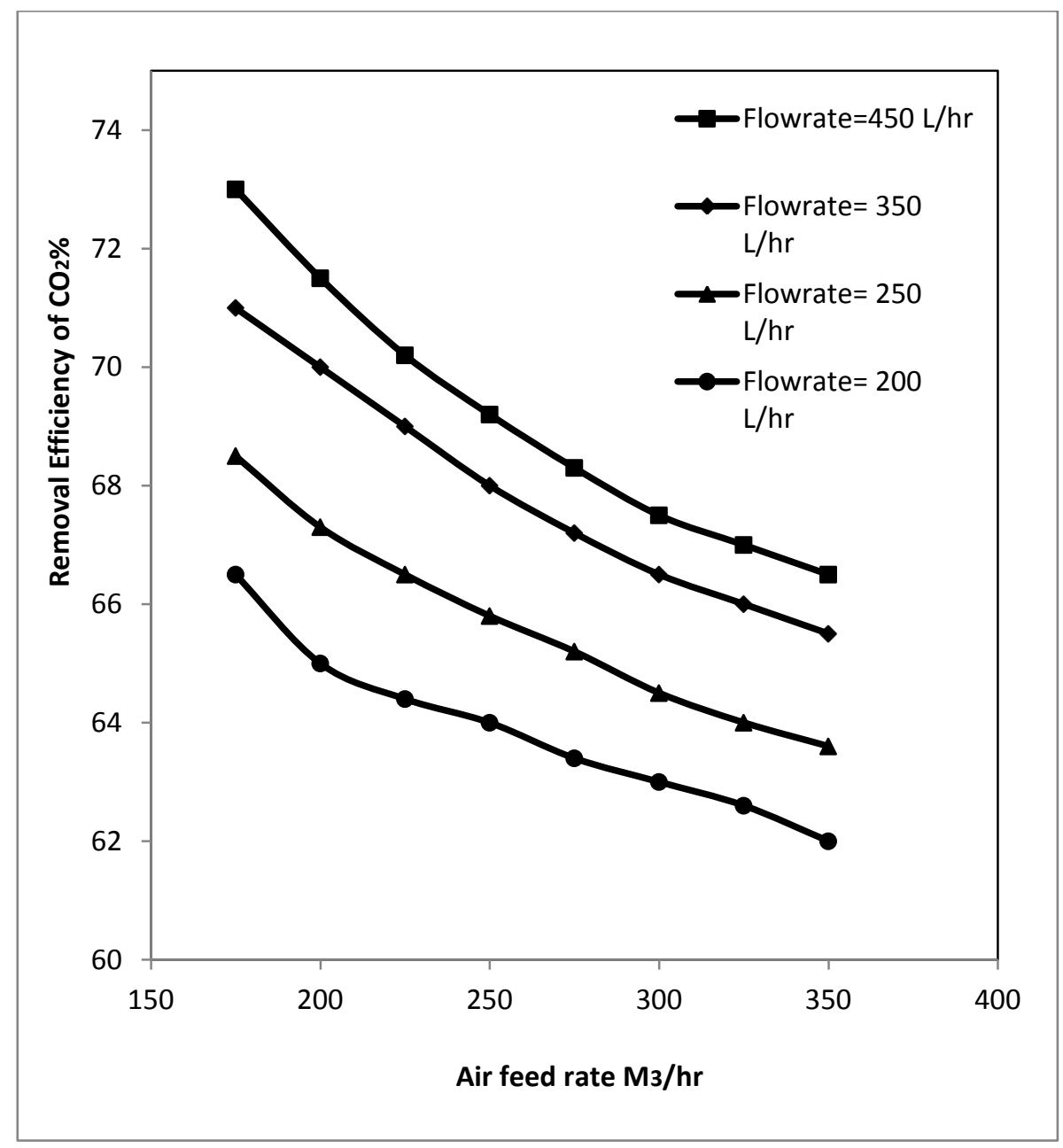

Figure (4) the effect of the air feed rate on the removal efficiency of $\mathrm{CO}_{2}$

Figure 5 show that the increases of concentration of carbon dioxide in the liquid feed will decrease the removal efficiency of $\mathrm{CO}_{2}$. If high removal efficiency is required the liquid flow rate or the amine concentration should be increased. [9] 


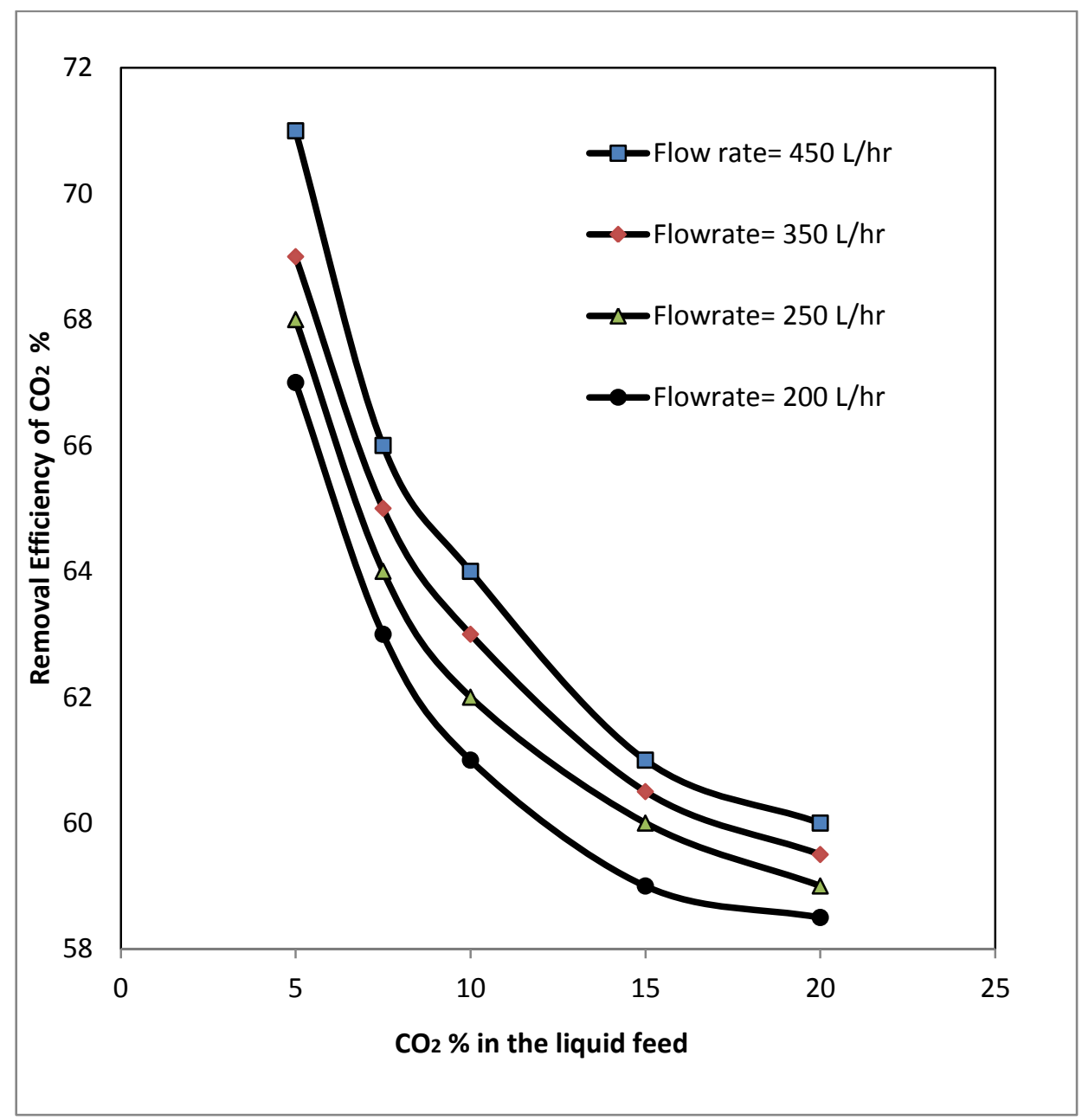

Figure (5) the effect of $\mathrm{CO}_{2} \%$ in the liquid feed on the removal efficiency of $\mathrm{CO}_{2}$

Figure 6 shows that when the loading of $\mathrm{CO}_{2}$ in the liquid phase reduced from 0.35 to 0.15 $\left(\mathrm{molCO}_{2} / \mathrm{mol}\right.$ MEA), while keeping all other conditions approximately the same;

$\mathrm{CO}_{2}$ removal efficiency will increase from 57 to $67 \%$. This increase is due to the availability of more free absorbent for the reaction with the absorbed $\mathrm{CO}_{2}$ in the gas phase. And that explain the important of the stripping unit after the absorption unit to separate free $\mathrm{CO}_{2}$ and as a result the regeneration the MEA. [9] 


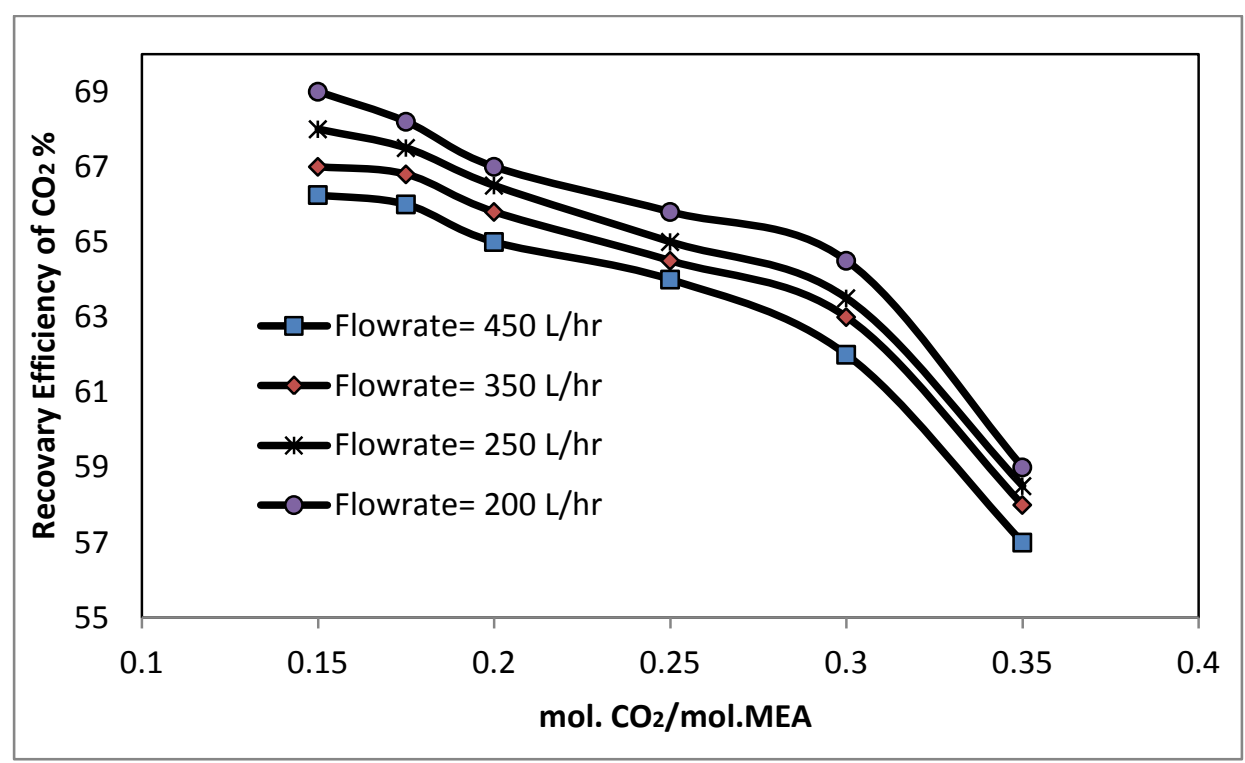

Figure (6) the effect of the ratio of $\left(\mathrm{CO}_{2} / \mathrm{MEA}\right)$ in the Liquid feed on the removal efficiency of $\mathrm{CO}_{2}$

\section{$\underline{\text { Conclusion }}$}

1. The highest removal efficiency of $\mathrm{CO}_{2}$ from mixture of $\mathrm{CO}_{2}$ and air could be achieved by increasing the liquid flow rate with high MEA concentration.

2. Reducing the air flow rate as possible according to the operating condition will increase the removal efficiency of $\mathrm{CO}_{2}$.
3. The absorption ability of MEA increase as its concentration in the liquid phase increase but not linearly as much as might be expected. that explain the important of the stripping unit after the absorption unit to separate free $\mathrm{CO}_{2}$ and as a result the regeneration the MEA. 


\section{References}

1. Dan G. Chapel and Carl L. Mariz,1999, Canadian Society of Chemical Engineers annual meeting, Saskatoon, Saskatchewan, Canada.

2. Hopson, Steve,1985, "Amine Inhibitor Copes with Corrosion," Oil \& Gas Journal, Vol. 83, No. 26, pp. 44-47.

3. Aboudheir, D.de montigny, P. Tontiwachwuthikul and A Chakma, process system laboratory, Faculty of Engineering, University of Regina, Canada, 1998," Gas Technology Symposium held in Calgary, Alberta, Canada 15-18.

4. Fadil H. Faraj and Alyaa K.Mageed, 2009,"The Effect of Surfactant Concentration on the Rate of $\mathrm{CO}_{2}$ Absorption by Carbonate Solution in Packed Tower" Eng. \& Tech. Journal,Vol.27, No. 6 .

5. Astarita, G., Savage, D., and Bisio, A., 1983,: Gas Treating with Chemical Solvents, John Wiley \& Sons, New York.

6. Sarmad Foad Jaber (Journal of engineering),2009, a Scientific Refereed Journal Published by: College of Engineering - university of Baghdad. No.4, Vol.15.

7. Adil. A. Al-Hemiri and Firas N. Hassan" Iraqi Journal for Chemical and Petroleum Engineering" Vol.10 No.4 P(57-62)

8. Kohl, A., and Nielsen, B., 1997,: Gas Purification, fifth edition, Gulf Publishing Company, Houston, Texas.

9. Jou F. Y., Mather A. E., and Otto F. D.,1995, The solubility of CO2 in 30 mass percent monoethanolamine solution, Can. Jour, of Chem. Eng., (73) pp 140-147.

10. Austgen D. M., Rochelle G. T., Peng, X. and Chen C. C. 1989, Model of vaporliquid equilibria for aqueous acid gas - alkanolamines systems using the electrolyte- NTRL equation, Ind. Eng., Chem. Res,, (28) pp 1060-1073

11. Khan, M. Simioni , S. van Zijll de Jong, S. Kentish and G. Stevens" CRC for Greenhouse Gas Technologies" Department of Chemical and Biomolecular Engineering, Melbourne University Parkville 3010, Australia. 